\title{
Sex ratio skewing of offspring in families with hereditary susceptibility to breast cancer
}

\author{
S M Domchek, S L Merillat, J Tigges, A J Tweed, M Weinar, J Stopfer, B L Weber
}

J Med Genet 2005;42:51 1-513. doi: 10.1136/jimg.2004.027722

T he function of BRCAl is complex and includes roles in DNA damage repair, cell cycle control, regulation of transcription, and X chromosome inactivation. ${ }^{12}$ TSIX is thought to control $\mathrm{X}$ chromosome inactivation by blocking the accumulation of XIST on the active $\mathrm{X}$ chromosome. ${ }^{3}$ BRCAl co-localises with XIST inactive X chromosomes (Xi) and stabilises $\mathrm{Xi}$. Because of this interaction, the loss of BRCAl is associated with altered Xi chromatin structure and increased expression of silenced Xi genes. ${ }^{12}$ Mouse models have suggested a link between aberrant $X$ chromosome inactivation and sex ratio skewing, with a bias towards male births when TSIX activity is abolished. ${ }^{3}$ In addition, nonrandom $\mathrm{X}$ chromosome inactivation has been seen in BRCAI mutation carriers with ovarian cancer. ${ }^{4}$ With these data as background, a skewed sex ratio in offspring of BRCAl mutation carriers was reported, ${ }^{5}$ with a bias towards females, compared with offspring of women with BRCA2 mutations and those without mutations in either gene. Others have not found a difference in the sex ratios of offspring of BRCAI and $B R C A 2$ mutation carriers. ${ }^{6-8}$ Here, we analysed the sex ratio of offspring in a large cohort of BRCAI and BRCA2 mutation carriers, as well as in HBOC families who tested negative for $B R C A 1$ and BRCA2 mutations or were not tested.

\section{METHODS}

\section{Database}

We included data from 1276 families evaluated between 1992 and 1994 (University of Michigan) and between 1994 and 2003 (University of Pennsylvania) in breast cancer risk evaluation clinics and considered to be at increased risk for having a breast cancer susceptibility gene mutation. Individuals were either self referred or physician referred for assessment of inherited susceptibility to breast or ovarian cancer. All individuals providing data signed their informed consent before genetic testing and entry into our database, which includes detailed pedigree information. Data collection between 1992 and 1994 was done with the approval from the University of Michigan institutional review board; subsequent data collection and analyses were done with approval of the University of Pennsylvania institutional review board.

All tested individuals had at least a $10 \%$ likelihood of having a BRCA1 or BRCA2 mutation, based on prevalence tables or various prediction models (reviewed by Domchek et $\left.a l^{9}\right)$. Untested individuals also had at least a $10 \%$ prior probability of having a detectable BRCAl or BRCA2 mutation, based on one or more of the following criteria:

- both breast and ovarian cancer in the same lineage of a three generation pedigree;

- at least one breast cancer diagnosis before age 35;

- at least one case of male breast cancer;

- at least three breast cancers in the same lineage diagnosed before age 60;

- prior probability of a BRCA1 or BRCA2 mutation calculated as above;

\section{Key points}

- A previous report suggested that there is a skewed sex ratio in offspring of BRCA1 mutation carriers compared with BRCA2 carriers or families with evidence of hereditary breast and ovarian cancer (HBOC) but without known mutations, possibly because of BRCA1 involvement in $\mathrm{X}$ chromosome inactivation. This association was investigated in a large cohort of $\mathrm{HBOC}$ families.

- Of the 795 offspring of 180 BRCA 1 mutation carriers, $57.6 \%$ were female; in 268 offspring of 99 BRCA2 mutation carrier offspring, $54.1 \%$ were female $(p=0.32)$.

- In 997 mutation negative or untested families, $57.4 \%$ and $59.1 \%$ of offspring, respectively, were female $(p=0.93, p=0.50)$.

- In BRCA2 mutation carriers, mutations in the $3^{\prime}$ end of the gene (exons 12-27) were associated with a significant reduction in female offspring $140.3 \%$ female) compared with $5^{\prime}$ mutations (exons 1-11) (58.7\% female, $p=0.009)$, and compared with all other $\mathrm{HBOC}$ families, suggesting that BRCA2 may play an as yet undefined role in $X$ chromosome inactivation or other sex determination mechanisms.

- breast cancer with any other primary cancer in the same individual. ${ }^{10}$

All patients were offered clinical testing for BRCAl and BRCA2 mutations; 668 of the 1276 families were tested for $B R C A 1$ and BRCA2 mutations. Of these, 180 families had BRCA1 mutations (26.9\%), 99 had BRCA2 mutations (14.8\%), and 389 had no detectable mutation in either gene (58.2\%). Families identified with variants of unknown significance (VUS) were not included with these 1276 families. In all, 608 families opted not to undergo testing.

\section{Genetic testing}

Mutation testing methods included direct sequencing in 56\% of individuals (either comprehensive or screening for the three Ashkenazi Jewish founder mutations; Myriad Genetics, Utah, USA); conformation sensitive gel electrophoresis (CSGE) in 37\% ${ }^{11}$; and other methods in 7\% (Southern blot analysis, single stand conformational polymorphism analysis, or protein truncation assay). ${ }^{12}$ The same proportion of individuals was tested by direct sequencing in the mutation positive and mutation negative groups (both $56 \%$ ).

Abbreviations: CSGE, conformation sensitive gel electrophoresis; $\mathrm{HBOC}$, hereditary breast and ovarian cancer 
Table 1 Sex ratio in hereditary breast and ovarian cancer families

\begin{tabular}{|c|c|c|c|c|c|c|c|}
\hline & Families & Individuals & $\begin{array}{l}\text { Tested } \\
\text { mutation } \\
\text { carriers }\end{array}$ & $\begin{array}{l}\text { Obligate } \\
\text { mutation } \\
\text { carriers }\end{array}$ & $\begin{array}{l}\text { Total } \\
\text { offspring }\end{array}$ & Female offspring & ${ }^{*}$ p Value \\
\hline BRCA1 & 180 & 475 & 453 & 22 & 795 & $458(57.6 \%)$ & \\
\hline BRCA2 & 99 & 173 & 172 & 1 & 268 & 145 (54.1\%) & 0.32 \\
\hline All tested negative & 389 & 431 & - & - & 556 & 319 (57.4\%) & 0.93 \\
\hline Affected, tested negative & 329 & 355 & - & - & 496 & $288(58.1 \%)$ & 0.87 \\
\hline Untested (affected, untested) & 608 & 1315 & - & - & 1459 & $862(59.1 \%)$ & 0.50 \\
\hline
\end{tabular}

\section{Pedigree analysis}

Offspring were counted through query of our Progeny database. All offspring of obligate and test confirmed BRCA1 and BRCA2 mutation carriers were counted. In the tested negative group, offspring of all tested individuals were counted. In the untested group, offspring of all individuals affected with breast or ovarian cancer were included.

\section{Statistical methods}

The $\chi^{2}$ test was used to evaluate differences in offspring ratios. STATA (release 8.0, Stata Corporation, College Station, Texas, USA) was used for all statistical analyses.

\section{RESULTS}

Of 795 offspring of BRCA1 mutation carriers, 458 (57.6\%) were female, while of 268 offspring of BRCA2 mutation carriers, $145(54.1 \%)$ were female (percentage of female offspring not significantly different, $\mathrm{p}=0.32$ ). In families testing negative, 319 of 556 offspring (57.4\%) were female. This ratio was unchanged when we restricted counting to offspring of individuals testing negative who were affected by breast or ovarian cancer, who accounted for $85 \%$ of those testing negative (288 of 496; 58.1\%). Likewise, 862 of 1459 offspring $(59.1 \%)$ of individuals affected by breast or ovarian cancer in families not tested for BRCA1 or BRCA2 were female. This ratio was not significantly different from that in offspring of BRCAl mutation carriers (table 1).

Of 180 families with BRCAl mutations, 94 (52.2\%) had one of the Ashkenazi Jewish founder mutations (68 with 185delAG, 26 with 5832insC). The sex ratio was not significantly different in the offspring of carriers of these specific BRCAl mutations compared with other BRCAl mutations (data not shown). Forty seven of 99 families (47.5\%) with BRCA2 mutations had the Ashkenazi Jewish founder mutation 6174delT. Interestingly, 6174delT mutation carriers had a greater proportion of female offspring than carriers of other BRCA2 mutations (72/117 (61.5\%) v 73/151 $(48.3 \%), p=0.032$ ) (table 2). Thus we asked whether positional effects might account for this difference. This analysis revealed that the offspring of individuals with mutations proximal to and including exon 11 (encompassing 6174delT) were significantly more likely to be female. Indeed, we found that 118 of 201 offspring $(58.7 \%)$ in families with 5' mutations (exons 1-11, which includes 6174delT) were female, while 27/67 (40.3\%)offspring of those with mutations at the $3^{\prime}$ end (exons 12-27) were female $(p=0.009)$. No positional effect was seen in analysis of BRCAl mutations (data not shown).

\section{DISCUSSION}

de la Hoya and colleagues examined the sex distribution of offspring in 17 families with BRCAl mutations and in 15 families with BRCA2 mutations seen in their risk evaluation clinic, and reported a skewed ratio favouring female offspring in BRCAl mutation carriers (table 3). ${ }^{5}$ In contrast, using a larger, statistically more powerful dataset, we found no difference in sex ratios in any of the three groups of HBOC families we analysed when the groups were analysed as a whole, although all groups had an excess of female offspring probably reflecting ascertainment bias. However, in evaluating potential biases stemming from overrepresentation of Ashkenazi founder mutations in our dataset, we did find that offspring sex ratios of $B R C A 2$ mutation carriers varied depending on the position of the mutation, with a decrease in female offspring associated with mutations in the $3^{\prime}$ end of $B R C A 2$. As the percentage of female offspring of individuals with $5^{\prime} B R C A 2$ mutations is similar to that of BRCA1 mutation carriers and others with $\mathrm{HBOC}$, it seems more likely that those with 3' BRCA2 mutations would have a decrease in female offspring, although it cannot be excluded that this is related to an excess of male offspring.

In considering other sources of bias in our dataset, it should be noted that offspring under the age of 18 are not kept in our database, for consent and confidentiality reasons. However, both female and male offspring under 18 are deleted from the pedigrees and therefore this practice should not induce a sex bias.

In the study by de la Hoya and colleagues, the number of BRCA2 mutation carriers was small $(\mathrm{n}=15)$ and there were no 6174delT mutation carriers in the sample set. When we excluded 6174delT mutations from our analysis, which represent the majority of $5^{\prime} B R C A 2$ mutations in our dataset, the trend persisted but we lost the statistical power to see a positional effect and our results appear similar to those of de la Hoya. Thus both small overall sample size and absence of 6174delT mutation carriers in the Spanish dataset may explain the discrepancies between these studies. However, we cannot exclude a mutation specific effect of 6174delT.

Table 2 BRCA2 mutation carrier offspring data by mutation position

\begin{tabular}{llllll}
\hline & Families & Individuals & Total offspring & Female offspring & p Value \\
\hline All BRCA2 & 99 & 174 & 268 & $145(54.1 \%)$ & \\
6174delT & 47 & 71 & 117 & $72(61.5 \%)$ & 0.032 \\
Other BRCA2 & 52 & 103 & 151 & $73(48.3 \%)$ & \\
Exons 1-11* & 82 & 138 & 201 & $118(58.7 \%)$ & 0.009 \\
Exons 12-27 & 17 & 36 & 67 & $27(40.3 \%)$ & \\
Exons 1-11 excluding 6174delT & 35 & 67 & 84 & $46(54.7 \%)$ & 0.077 \\
Exons 12-27 & 17 & 36 & 67 & $27(40.3 \%)$ & \\
\hline *Includes 6174delT. & & & & & \\
\hline
\end{tabular}


Table 3 Comparison of sex ratio data

\begin{tabular}{|c|c|c|c|c|c|}
\hline & Total families & Mutation & Male & Female & p Value* \\
\hline \multirow[t]{2}{*}{$\begin{array}{l}\text { de la Hoya et } \\
a l^{5}\end{array}$} & 17 & BRCA1 & $65(33 \%)$ & $133(67 \%)$ & \\
\hline & $\begin{array}{l}15 \\
36\end{array}$ & $\begin{array}{l}\text { BRCA2 } \\
\text { Tested negative }\end{array}$ & $\begin{array}{l}85(47 \%) \\
315(48 \%)\end{array}$ & $\begin{array}{l}97(53 \%) \\
344(52 \%)\end{array}$ & $\begin{array}{r}0.006 \\
<0.001\end{array}$ \\
\hline UPenn & $\begin{array}{l}180 \\
99 \\
389 \\
608\end{array}$ & $\begin{array}{l}\text { BRCA1 } \\
\text { BRCA2 } \\
\text { Tested negative } \\
\text { Untested }\end{array}$ & $\begin{array}{l}337(42 \%) \\
123(46 \%) \\
237(42.6 \%) \\
597(40.9 \%)\end{array}$ & $\begin{array}{l}458(58 \%) \\
145(54 \%) \\
319(57.4 \%) \\
862(59.1 \%)\end{array}$ & $\begin{array}{l}0.32 \\
0.93 \\
0.50\end{array}$ \\
\hline
\end{tabular}

When the offspring ratio in our study participants was compared with US census data from 2000 (www.census.gov) an excess of female offspring is evident in all families seen in our breast cancer risk evaluation clinic $(p<0.0001)$. The most likely explanation for the overall increased ratio of female offspring of women attending breast cancer risk evaluation clinics is a selection bias for participation, as a significant predictor for use of genetic testing is the perception of benefit to family members. ${ }^{13}$ With breast and ovarian cancer susceptibility being the most widely known risks associated with BRCA1 and BRCA2 mutations, many patients give concern for their daughters as their primary reason for presenting for risk evaluation and genetic testing. As overall cancer risks for male mutation carriers are lower, ${ }^{14}$ woman with only sons may be less likely to seek evaluation than women with one or more daughters. Alternatively, mutations in genes associated with hereditary breast and ovarian cancer syndromes could indeed be associated with a skewed offspring ratio, perhaps because of abnormalities in $\mathrm{X}$ chromosome inactivation in mutation carriers.

These data suggest the possibility that expressing truncated BRCA2 has different biological consequences from expressing no BRCA2 at all. This explanation is consistent with the recent observation that individuals homozygous for BRCA2 mutations have Fanconi anaemia, but it appears that at least one mutation in a BRCA2 homozygote must be in the $3^{\prime}$ region of the gene or the embryo may not survive. ${ }^{15}{ }^{16}$ In addition, a polymorphism in exon 10 of BRCA2 $(\mathrm{N} 372 \mathrm{H})$ has been reported to result in an excess of male births. Although this altered sex ratio is in the opposite direction to what we have observed, this may reflect a difference between polymorphisms and deleterious mutations resulting in protein truncation. ${ }^{17}$

\section{Conclusions}

We found no difference overall in sex ratios of offspring of $B R C A 1$ mutation carriers, BRCA2 mutation carriers, and HBOC families without a known BRCAl or BRCA2 mutation. However, differences in offspring sex ratios became apparent when BRCA2 mutation carriers where analysed by mutation position. These data, although very preliminary, are intriguing and suggest that additional functional analysis of BRCA2 may reveal a role for BRCA2, as well as BRCA1, in $\mathrm{X}$ inactivation or in other sex determination mechanisms.

\section{ACKNOWLEDGEMENTS}

This research was supported by NIH award K12-HD43459 to SMD, and by the Breast Cancer Research Foundation and the Abramson Family Cancer Research Institute to BLW.

\section{Authors' affiliations}

S M Domchek, S L Merillat, J Tigges, A J Tweed, M Weinar, J Stopfer, B L Weber, Abramson Cancer Center, University of Pennsylvania, Philadelphia, Pennsylvania, USA

Competing interests: none declared
Correspondence to: Dr Susan Domchek, 14 Penn Tower, Hospital of the University of Pennsylvania, 3400 Spruce St, Philadelphia, PA 19104, USA; susan.domchek@uphs.upenn.edu

Received 30 September 2004

Revised version received 3 January 2005

Accepted for publication 5 January 2005

\section{REFERENCES}

1 Venkitaraman AR. Cancer susceptibility and the functions of BRCA1 and BRCA2. Cell 2002;108:171-82.

2 Ganesan S, Silver DP, Greenberg RA, Avni D, Drapkin R, Miron A, Mok SC, Randrianarison V, Brodie S, Salstrom J, Rasmussen TP, Klimke A, Marrese C, Marahrens Y, Deng CX, Feunteun J, Livingston DM. BRCA1 supports XIST RNA concentration on the inactive $X$ chromosome. Cell 2002;111:393-405.

3 Lee JT. Homozygous Tsix mutant mice reveal a sex-ratio distortion and revert to random X-inactivation. Nat Genet 2002;32:195-200.

4 Buller RE, Sood AK, Lallas T, Buekers T, Skilling JS. Association between nonrandom X-chromosome inactivation and BRCA1 mutation in germline DNA of patients with ovarian cancer. J Natl Cancer Inst 1999;91:339-46.

5 de la Hoya M, Fernandez JM, Tosar A, Godino J, Sanchez de Abajo A, Vidart JA, Perez-Segura P, Diaz-Rubio E, Caldes T. Association between BRCA1 mutations and ratio of female to male births in offspring of families with breast cancer, ovarian cancer, or both. JAMA 2003;290:929-31.

6 Struewing JP, Hartge P, Wacholder S, Tucker MA, Greene MH. BRCA 1 and sex ratio. Eur J Hum Genet 2004;12:663-7.

7 Feunteun J, Chompret A, Helbling-Leclerc A, Stoppa-Lyonnet D, Belotti M, Nogues $C$, Bonaiti-Pellie $C$. Sex ratio among the offspring of BRCA mutation carriers. JAMA 2004;292:687-8.

8 Gal I, Sadetzki S, Gershoni-Baruch R, Oberman B, Carp H, Papa MZ, Diestelman-Menachem T, Eisenberg-Barzilai S, Friedman E. Offspring gender ratio and the rate of recurrent spontaneous miscarriages in Jewish women at high risk for breast/ovarian cancer. Am J Hum Genet. 2004;74: 1270-5, Epub 2004 Apr 28.

9 Domchek SM, Eisen A, Calzone K, Stopfer J, Blackwood A, Weber BL. Application of breast cancer risk prediction models in clinical practice. J Clin Oncol 2003;21:593-601.

10 Shih HA, Nathanson KL, Seal S, Collins N, Stratton MR, Rebbeck TR, Weber BL. BRCA1 and BRCA2 mutations in breast cancer families with multiple primary cancers. Clin Cancer Res 2000;6:4259-64.

11 Couch FJ, DeShano ML, Blackwood MA, Calzone K, Stopfer J, Campeau L, Ganguly A, Rebbeck T, Weber BL. BRCAl mutations in women attending clinics that evaluate the risk of breast cancer. N Engl J Med 1997;336:1409-15.

12 Unger MA, Nathanson KL, Calzone K, Antin-Ozerkis D, Shih HA, Martin AM, Lenoir GM, Mazoyer S, Weber BL. Screening for genomic rearrangements in families with breast and ovarian cancer identifies BRCA1 mutations previously missed by conformation-sensitive gel electrophoresis or sequencing. Am J Hum Genet 2000;67:841-50

13 Armstrong K, Calzone K, Stopfer J, Fitzgerald G, Coyne J, Weber B. Factors associated with decisions about clinical BRCA1/2 testing. Cancer Epidemiol Biomarkers Prev 2000;9:1251-4

14 Thompson D, Easton DF. Cancer incidence in BRCA1 mutation carriers. J Natl Cancer Inst 2002;94:1358-65.

15 Offit K, Levran O, Mullaney B, Mah K, Nafa K, Batish SD, Diotti R, Schneider H, Deffenbaugh A, Scholl T, Proud VK, Robson M, Norton L, Ellis N, Hanenberg $H$, Auerbach AD. Shared genetic susceptibility to breast cancer, brain tumors, and Fanconi anemia. J Natl Cancer Inst 2003;95:1548-51.

16 Howlett NG, Taniguchi T, Olson S, Cox B, Waisfisz Q, De Die-Smulders C, Persky N, Grompe M, Joenje H, Pals G, Ikeda H, Fox EA, D'Andrea AD. Biallelic inactivation of BRCA2 in Fanconi anemia. Science 2002;297:606-9, Epub 2002 Jun 13.

17 Healey CS, Dunning AM, Teare MD, Chase D, Parker L, Burn J, ChangClaude J, Mannermaa A, Kataja V, Huntsman DG, Pharoah PD, Luben RN, Easton DF, Ponder BA. A common variant in BRCA2 is associated with both breast cancer risk and prenatal viability. Nat Genet 2000;26:362-4. 